\title{
RESEARCH ON THE EFFECTIVENESS OF THE INTRODUCTION APPROACH ON STUDENTS WITH MEDICAL PROTOCOLS
}

\author{
G. Dyakova $^{1}$, T. Dyakov ${ }^{2}$ \\ ${ }^{1}$ Department of Physical Education and Sport, Faculty of Economics, Trakia University, \\ Stara Zagora, Bulgaria \\ ${ }^{2}$ Chicago, Illinois, USA
}

\begin{abstract}
The aim of the investigation is by conducting a survey and analysis of the percentage of students with medical reports, to assess the effectiveness of the approach introduced. We have monitored the relative proportion of students with medical protocols to determine the effectiveness of an introduced approach. The study was conducted with 4194 students - 1624 men and 2570 women from the Faculty of Economics, the Faculty of Veterinary Medicine and the Faculty of Agriculture at Trakia University. Applied are the following methods: Theoretical analysis; Comparative analysis of percentages; Graphic analysis. We conducted monitoring, analysis and evaluation for 19 academic years of the relative proportion of students with medical protocols. The results confirm categorically effectiveness of the approach to students with medical protocols.
\end{abstract}

Key words: Physical education and sports, monitoring, diseases.

\section{INTRODUCTION}

According to Art. 57. (1) of the Physical education and sports law, Published on SN, issue 86, dd 18.10.2018. „Physical activity, physical education and sports at higher schools are a part of the education of students under the form of obligatory and elective classes of minimum attended educational hours of the obligatory classes of 60 hours per year for the students, educated for acquiring the educational-qualification degree „Master“ (1).

Students are a very special part of our society. They are our future and we care for them with tender. Being Lecturers on Physical culture and sports, we work with students who are healthy and students who have severe or chronic diseases. Unfortunately, there are some students who are not ill, but they present themselves as being such. It is provoked by the

\footnotetext{
*Correspondence to: Galina Dyakova, Department of Physical Education and Sport, Faculty of Economics, Trakia University, Stara Zagora, Bulgaria, +359 886846370, E-mail: galinapdyakova@bitex.bg
}

vicious practice in the past for Physical culture and sports class to be deemed by this contingent, as being a "leisure" one.

The inclusion of students with health problems in the classes of Physical Education and Sports could enhance the motive activity and their quality of life, in order to combine their education with the treatment and prophylaxis of the diseases and to form up a better values orientation towards the physical culture and sport $(2,3)$.

This report represents a third stage of a research, carried out for a long period of time.

- During the first stage, we have investigated the trends and made prognosis, connected to the exemption of students from PES classes (4).

- During the second stage we have introduced an approach for overcoming the "exemption of students from PES classes" (5).

- During the present, third stage, we have monitored the percentage of students with 
medical reports, in order to establish the effectiveness of the introduced approach.

The investigation carried out by us in 2006 established the trends of increasing the number of students, looking for ways to obtain medical papers, without having any diseases (6-8). These trends proved to be too alarming. Departments on Physical culture and sports in higher schools are not in a position to revise the cases for issuing medical reports, but for overcoming of these trends, we have undertaken certain measures. The notion, „student with a medical report", has filled in with new content. In 2008, a new approach was experimented to this category of students, including:

- Requirement for obligatory presence at Physical culture and sports classes.

- Recommendation of individual classes (during the lesson) with physical exercises according to the diagnosis entered in the medical report.

- For medical cases, excluding physical loading whatsoever, or by the will of the student alone, with a medical report, the class passes in Chess, Darts playing, or using of educational literature, connected with various types of sport from the educational programme on the subject, and knowing of the rules, as well as exercises developed for the most common diseases.

- During the fourth semester of "the students with medical reports" a possibility within two and a half weeks limit is given for nonpresence in the Physical education and sports classes, in order to develop two essays each, one connected with a type of sport and knowing of the rules, and another one of a healthy way of life. Papers are presented before a person with academic rank for assessment.

The information analysis made gives us a ground to formulate the work hypothesis, that the approach introduced will be effective.

The aim of the present investigation is by conducting a survey and analysis of the percentage of students with medical reports, to assess the effectiveness of the approach introduced.

Realization of the aim supposes solving of the following tasks:
DYAKOVA G., et al.

1. To carry out theoretical investigation of the information resources on the issue set.

2. To investigate the documents under review of Physical culture and sports Department, Trakia University.

3. To analyze and assess the results got.

\section{METHODS}

The investigation was carried out with 4194 students from the Trakia University - Stara Zagora within 10 educational years. Documents under review have been investigated for 2010/2011, 2011/2012, 2012/2013, 2013/2014, 2014/2015, 2015/2016, 2016/2017, 2017/2018, 2018/2019, 2019/2020 (9).

Data from other our investigations, within nine educational years has been applied 1992/1993; 1999/2000; 2003/2004; 2004/2005; 2005/2006; 2006/2007; 2007/2008; 2008/2009; $2009 / 2010$.

Subject of the investigation is the process of education on Physical education and sports of students with medical reports at higher schools.

Object of the investigation are the changes occurred in the percentage of students with medical reports.

Applied are the following methods: Theoretical analysis; Comparative analysis of percentages; Graphic analysis.

Thorough survey, analysis and assessment have been carried out of the percentage of students with medical reports within 19 educational years.

\section{RESULTS}

On Figure 1, data is put manifesting the percentages of students with documents of acute and chronic diseases. The first data available was registered for the educational year 1992/1993. The percentage of students, exempted from Physical education and sports classes (PCS) was 0,71\%. In 1999/2000 insignificant increasing was observed - $0,88 \%$. However, in the following three years high values are a fact, for $2003 / 2004-11,70 \%$, for $2004 / 2005$ - $17,76 \%$ and for 2005/2006 $22,96 \%$. In the educational year $2006 / 2007$ the percentage of the exempted from Physical culture and sports classes continues increasing, reaching the highest values for the period 
under investigation $-27,46 \%$. From the discussions held with students, we got informal information of discrepancy between the number of truly ill students and the number of the exempted ones, because of medical certificates.

The new experimental approach, introduced in the educational year 2008/2009, gave positive results and still in the first two years, the percentage of students with medical report changed to $11,98 \%$ for $2008 / 2009$ and $4,78 \%$ for 2009/2010. The introduction of the requirement for obligatory presence at the
DYAKOVA G., et al.

Physical culture and sports classes of students with presented medical papers, proving a disease, was the one that lead to reducing the searching of a way for obtaining of medical papers, without in fact having such diseases. The experimental approach contributed to getting a true idea of the really diseased students. Data from the investigation we have carried out throughout the long period of time after the introduction of the new approach, shows the descending gradation of the percentage of students with medical reports.

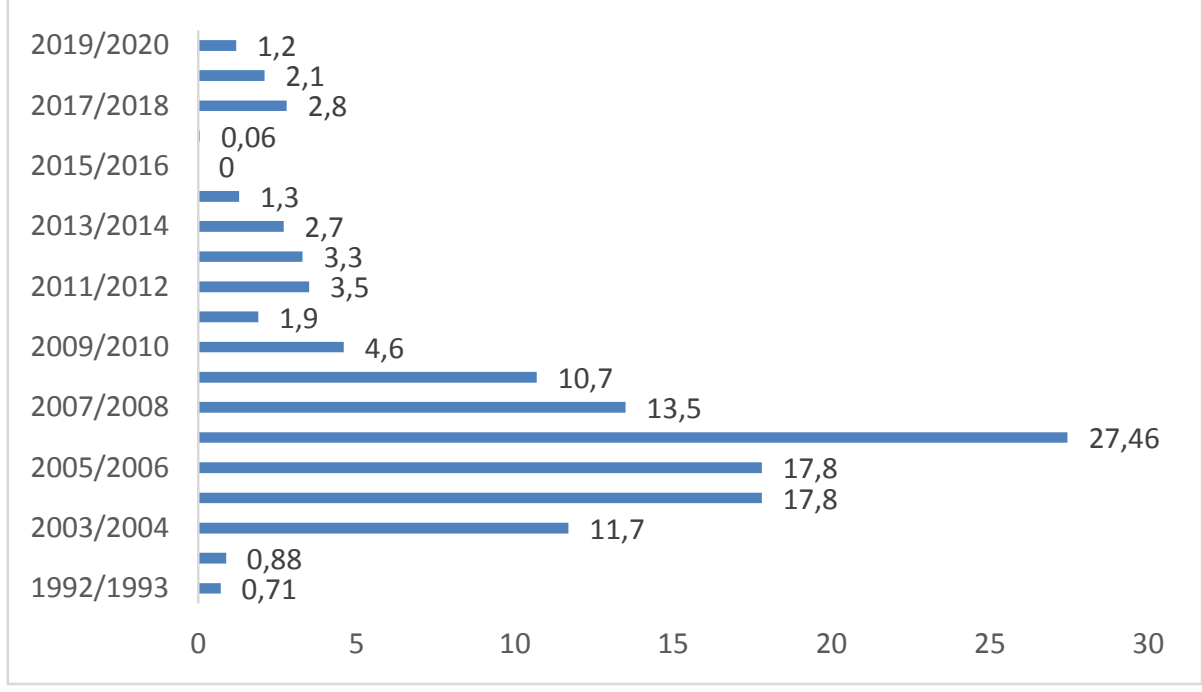

Figure. 1. Percentage of students with medical reports

On Figure 2, the high level of percentage of students /women/, presented medical reports prior the educational year 2008/2009 is evident, when the new approach was introduced /the period from 2003 till 2008/. In
$2005 / 2006$ was the peak of the percentage for this period $-35,5$. After the introduction of the new approach, and up to now, we observe a reduction of the percentage of students /women/ with presented medical reports.

Figure 2. Percentage of students (women) with medical reports

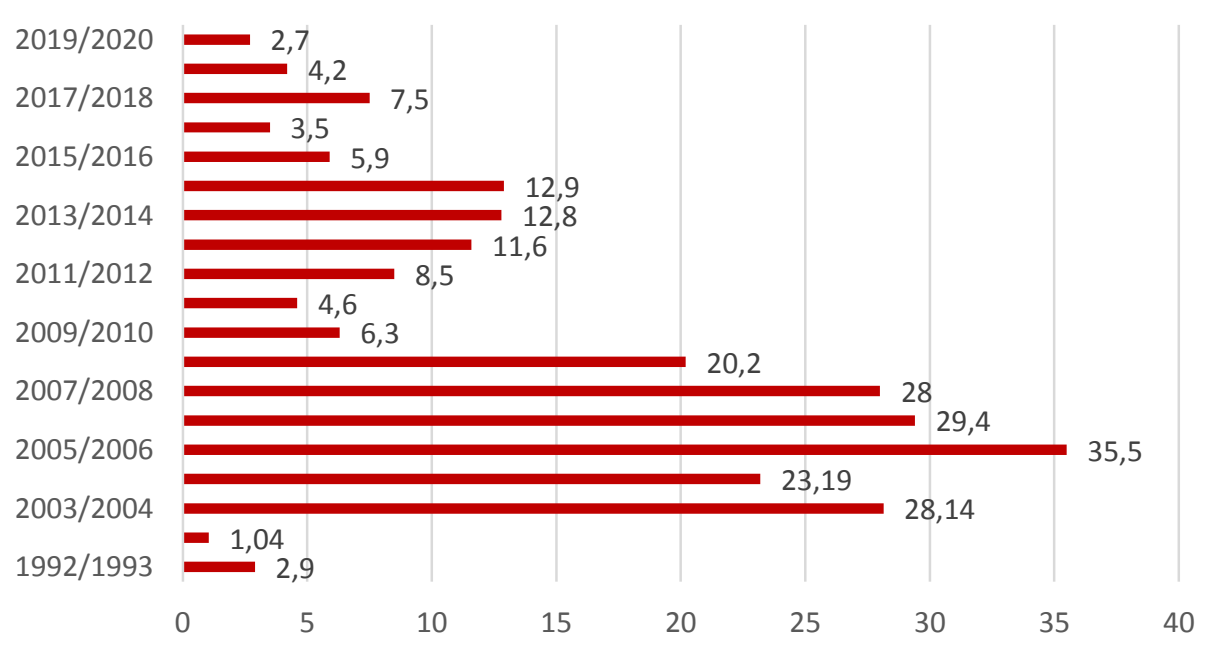


On Figure 3, the dynamics of the percentage of students with medical reports (men and women) is clearly presented. It is apparent that the percentage of women, presented medical certificate is higher than that of men throughout the whole period under investigation. Observed are the top years, the so called peak of presented medical
DYAKOVA G., et al. certificates, happened to be a reason for making an experiment with the new approach. The reduction of the percentage of students with medical report, both with women and men is apparent, as a result of this new approach. Results from the observation after the educational year 2008/2009 show the effectiveness of the approach chosen.

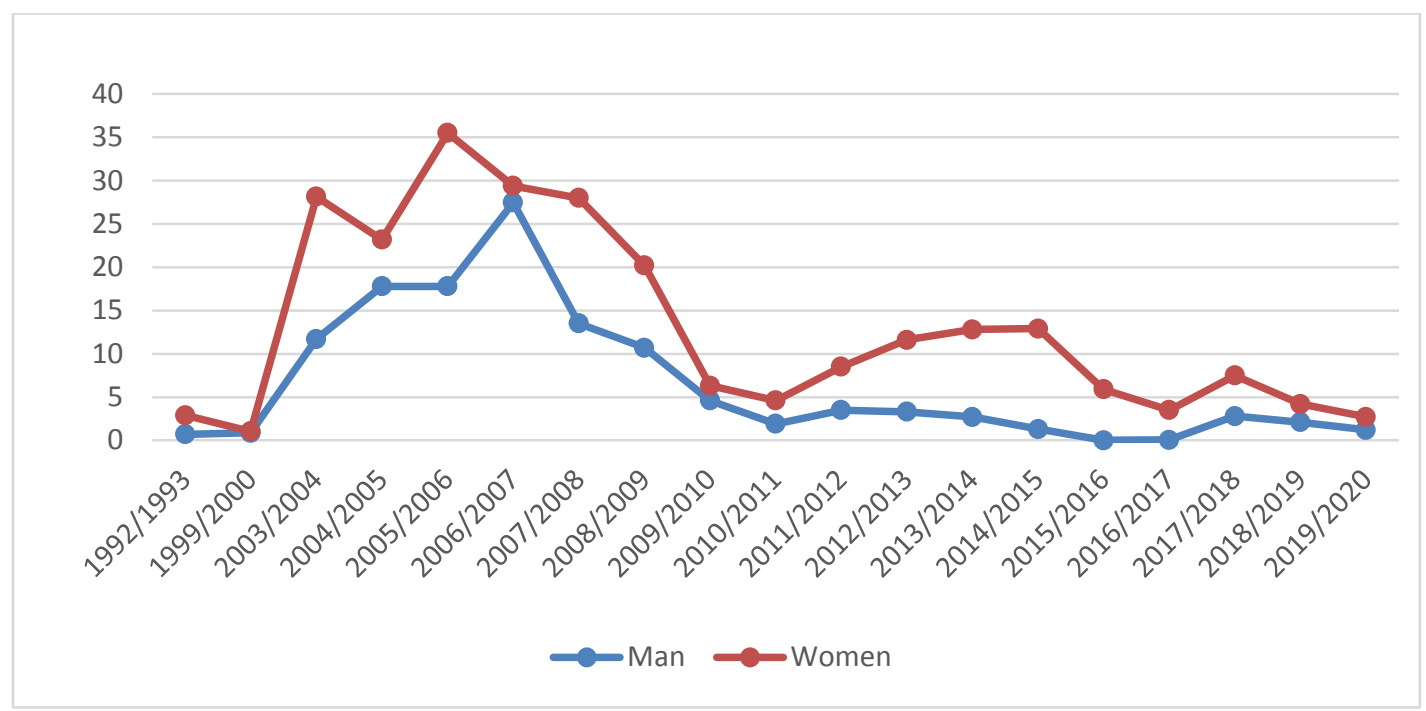

Figure 3. Dynamics of the percentage of students with medical reports (men and women)

On Figure 4, the average values of the percentage of students with medical reports for the 19-years period of investigation have been reflected - prior and after the monitoring carried out. From it, the reduction of the percentage in all three categories - students is clearly observed; students /women/ and students /men and women/, which proves the effectiveness of the approach introduced.

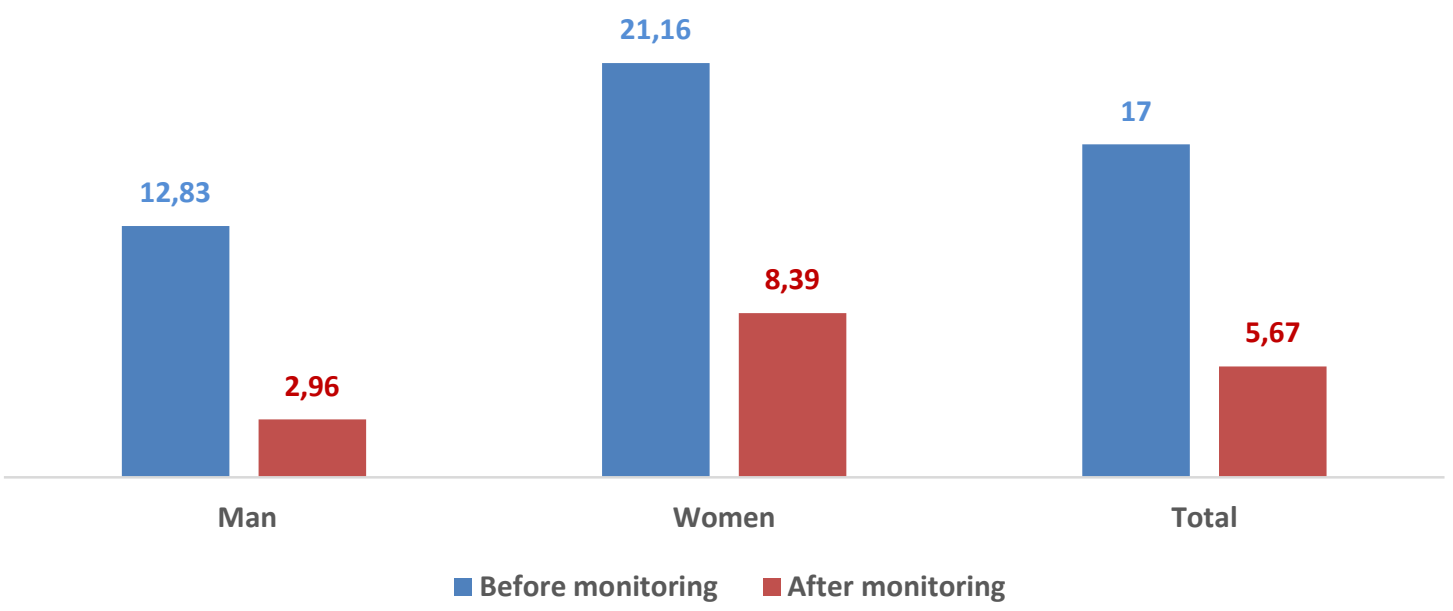

Figure 4. Average values of the percentage of students with medical reports (men and women)

CONCLUSIONThe monitoring carried out definitely confirms the effectiveness of the approach introduced to students with medical reports.
We recommend the application of the introduced approach as a suitable one both for higher schools and other levels of the educational system. 


\section{REFERENCES}

1. Physical culture and sports law. Published SN, issue 86, dd 18.10.2018.

2. Bozhkova, A., K. Vasilev. Research on the physical condition of students with abnormalities in their health status. $M A G$ SPORTS AND SCIENCE., Vol. 2, c. 103111, ISSN 1310-3393, C., 2014.

3. Bozhkova, A., K. Vasilev. Diagnostic analysis of health problems of students, released from the regular trainings on physical culture and sports. ACTIVITIES IN PHYSICAL EDUCATION AND SPORT - International Journal of Scientific and Professional Issues in Physical Education and Sport, Vol. 4/2, pp. 168-171, ISSN 1857-7687, Republic of Makedonia, http://fsprm.mk/apes-2014-vol-04-no-2/ 2014.

4. Dyakova, G. Exemption of students from Physical culture and sports classes - trends and prognosis. Mag. Sport and Science, S., copy 4., , p. 72-75, 2006.

5. Dyakova, G. Making experiment of an approach for overcoming of the phenomenon „exemption of students from
DYAKOVA G., et al. Physical culture and sports classes". Mag. Sport and Science, ISSN 1310-3303, extra copy 1, S., p. 48-53, 2011.

6. Dimitrov D, G. Belchev and N. Terzistoeva. Some considerations on issues, connected to the exemption of students from Physical culture and sports classes. VII scientific session of HMI, Pleven, 1987.

7. Dimitrov D, G. Belchev and N. Todorova, About some issues of work with the students exempted from Physical culture and sports classes, Issues of physical culture, 11 copy 1985.

8. Dimitrov D, G. Belchev and N. Todorova. Factors determining the attitude of the students exempted from Physical education classes to systematic and organized classes, with physical exercises, HIZVM (Higher Institute of Zootechnics and Veterinary Medicine - Stara Zagora Scientific papers v. XXXII , part II, 1988.

9. Report papers of Department "Physical education and sports"- Tr.U Stara Zagora for the educational years periods from 2010-2020. 